\title{
Tobacco control in the Eastern Mediterranean Region: the urgent requirement for action
}

\author{
Jawad A. Al-Lawati ${ }^{1}$ and Judith Mackay ${ }^{2}$
}

${ }^{1}$ Directorate General of Primary Health Care, Ministry of Health, Muscat, Oman. ${ }^{2}$ Director, Asian Consultancy on Tobacco Control, Hong Kong; and Senior Advisor, Vital Strategies. (Correspondence to: Judith Mackay: jmackayı@netvigator.com).

Citation: Al-Lawati JA; Mackay J. Tobacco control in the Eastern Mediterranean Region: the urgent requirement for action. East Mediterr Health J. 2020;26(1):6-8. https://doi.org/10.26719/2020.26.1.6

Copyright (C) World Health Organization (WHO) 2020. Open Access. Some rights reserved. This work is available under the CC BY-NC-SA 3.0 IGO license (https://creativecommons.org/licenses/by-nc-sa/3.o/igo).

The World Health Organization Framework Convention on Tobacco Control (WHO FCTC) was developed in response to the globalization of the tobacco epidemic, and contains measures to reduce the demand for tobacco as well as reducing its production, distribution, availability and supply. Currently, 19 of the 22 Eastern Mediterranean Region (EMR) countries are parties to the WHO FCTC (1).

In line with the WHO FCTC, the World Health Organization (WHO) introduced a set of six costeffective and high-impact measures that help countries to reduce demand for tobacco. Known as MPOWER, these measures include: Monitoring tobacco use and prevention policies, Protecting people from tobacco smoke, Offering help to quit tobacco use, Warning people about the dangers of tobacco, Enforcing bans on tobacco advertising, promotion and sponsorship, and Raising taxes on all tobacco products.

The WHO FCTC came into force in 2005, and 15 years later it is both important and opportune to take stock of the progress, review the practices, and highlight the gaps and the challenges facing tobacco control in the EMR. This is especially important given that, in the WHO's 2018 Global Report on Trends in Prevalence of Tobacco Smoking, the EMR was projected to be the only WHO Region (from a total of six WHO Regions worldwide) to see an increase in the prevalence of tobacco use among males (2). In addition, there is particular concern about a future rise in female prevalence, as indicated in the Global Youth Tobacco Surveys, which show a narrowing gender gap between rates of tobacco use in a number of countries in the Region (3).

To date there have been some notable highlights throughout the Region following the adoption of noncommunicable disease voluntary targets. So far, 13 countries have adopted the global target of a $30 \%$ relative reduction in the prevalence of current tobacco use in persons aged over 15 years by 2025 (4). Monitoring of the tobacco epidemic through recent and representative surveys for both adults and young people has been attained by 12 EMR countries (5), with $63 \%$ of the population now being 100\% protected from second-hand smoke in indoor public places by national legislations (6). A comprehensive ban on tobacco advertising, promotion and sponsorship has been implemented in 10 countries in the Region (5). An observatory has been established in Egypt to monitor and track tobacco advertising, promotion and sponsorship in Arabic language drama, and another two are currently under consideration (7). Medium to large pictorial cigarette packet warnings have been in implemented in 15 countries, with Saudi Arabia being the first country in the Middle East and Asia to require plain packing for all tobacco products. Over $91 \%$ of EMR countries offer some sort of support services for tobacco use cessation (5).

However, the EMR falls behind all other WHO regions in having the lowest average prices of tobacco products - an important factor when considering that decreasing affordability is the best-known measure to reduce uptake of smoking by young people $(5,8)$. In addition, there is an immediate and future concern about the growing popularity of waterpipe use in the EMR and the emerging epidemic of electronic nicotine delivery systems and heated tobacco products. The latter are becoming an increasing challenge globally and in the EMR countries, although a growing number of countries are banning e-cigarettes and similar vaping products over increasing public health concerns (9).

Despite relatively good progress in the Region on tobacco control, no EMR country has fully implemented either the key WHO FCTC articles or the six crucial MPOWER measures. Only six EMR countries (Egypt, Islamic Republic of Iran, Kuwait, Pakistan, Qatar and Saudi Arabia) have implemented at least three MPOWER measures at the highest level as defined by WHO (10). With the prevalence of tobacco use predicted to rise in the coming years (2), it is vital that much stronger action be undertaken now, or the tobacco epidemic will have immense negative health and economic consequences for EMR countries. If fully implemented and enforced, the MPOWER measures could significantly reduce smoking prevalence in the EMR (Figure 1), falling from $20.6 \%$ of the population in 2010 to a predicted $13 \%$ by 2030 (11).

By 2023, in keeping with the goals of the WHO Regional Strategy and Action Plan for Tobacco Control, all EMR countries are expected to have ratified the WHO FCTC and developed comprehensive, multisectoral national tobacco control strategies, plans, programmes and infrastructure for WHO FCTC implementation 


\section{Figure 1 Reduction in smoking prevalence in the EMR if WHO FCTC measures represented by MPOWER are fully implemented and} enforced

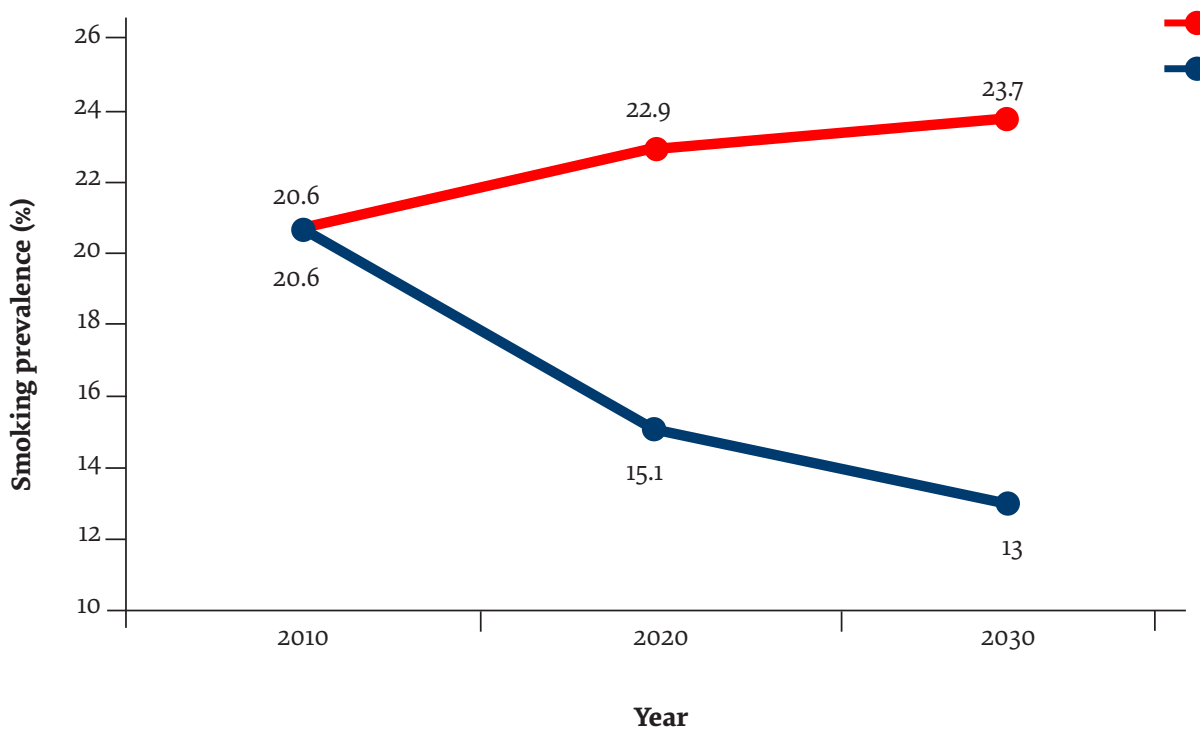

(12). However, this requires political commitment at the highest level of government throughout the Region. Furthermore, in accordance with the relevant articles of the WHO FCTC, it requires no less than immediate policy formulation and implementation of tax increases, creation of smoke-free areas in all indoor public places, schools and workplaces, and for a full ban on tobacco advertising, promotion and sponsorship.

It is also crucial to remember that WHO FCTC Article 5.3 precludes any involvement of the tobacco industry in formulating government policy for tobacco control (13). This applies to all branches of government, including the judiciary, the civil service and elected and appointed politicians. Many civil servants either simply fail to understand their obligations in this regard or choose to ignore this crucial undertaking. Successful and optimal implementation of Article 5.3 to eliminate the tactics of the tobacco industry in obstructing and undermining national and global tobacco control policies requires a multisectoral approach and deliberate collaboration among various stakeholder groups (e.g. government, civil society, and private sector). Since the WHO FCTC was signed by heads of states, it becomes the responsibility of the whole of government, not just the health ministry in each country, for its effective implementation. Failure to take the necessary measures will have repercussions on the health and economy of the populace of the EMR countries for decades to come. The task ahead for all EMR governments and civil society is certainly substantial, but not impossible to attain.

\section{References}

1. United Nations Treaty Collection: WHO Framework Convention on Tobacco Control Status. (https://treaties.un.org/pages/ViewDetails.aspx?src=TREATY\&mtdsg_no=IX-4\&chapter=9\&clang=_en, accessed 2 September 2019).

2. World Health Organization. WHO Global Report on Trends in the Prevalence of Tobacco Smoking 2018. Second Edition. Geneva: World Health Organization; 2018.

3. Tobacco Free initiative, Regional Office for the Mediterranean, World Health Organization. The truth about young people and tobacco. (http://www.emro.who.int/tfi/know-the-truth/young-people-and-tobacco.html\#youth, accessed 3 September 2019).

4. Technical Officer for Surveillance, Department of Noncommunicable Diseases and Mental Health, WHO Eastern Mediterranean Regional Office. Voluntary Global Targets, 2019 (personal communication).

5. World Health Organization. WHO report on the global tobacco epidemic, 2019: Offer help to quit tobacco use, summary of MPOWER measures. Geneva: World Health Organization; 2019:152.

6. El-Awa F, Bettcher DW, Al-Lawati JA, Alebshehy R, Gouda H, Fraser CP. The status of tobacco control in the Eastern Mediterranean Region: progress in the implementation of the MPOWER measures. East Mediterr Health J 2020;26(1):102-109

7. El-Awa FMS, Naga RAE, Labib S, Latif NA. Tobacco advertising, promotion and sponsorship in entertainment media: a phenomenon requiring stronger controls in the Eastern Mediterranean Region. East Mediterr Health J 2018;24:72-76.

8. World Health Organization Regional Office for Eastern Mediterranean (WHO/EMRO). Tobacco taxation in the Eastern Mediterranean Region. Cairo: WHO/EMRO; 2010 (http://applications.emro.who.int/dsaf/emropub_2010_1247.pdf?ua=1\&ua=1, accessed 6 September 2019). 
9. Global Centre for Good Governance in Tobacco Control. E-Cigarette ban \& regulation: Global Status as of October 2019 (https:// ggtc.world/2019/11/07/e-cigarette-ban-regulation-global-status-as-of-october-2019, accessed 15 January 2020).

10. Tobacco use: achieving the global target of 30\% reduction by 2025. East Mediterr Health J 2015;21(12):934-936.

11. World health Organization. Effects of meeting MPOWER requirements on smoking rates and smoking-attributable deaths. Geneva: world Health Organization; 2019 (http://www.emro.who.int/tfi/mpower/index.html, accessed 6 September 2019).

12. World Health Organization. Regional strategy and action plan for tobacco control reflecting the commitments of the WHO Framework Convention on Tobacco Control. Geneva: World Health Organization; 2019 (http://applications.emro.who.int/docs/ RC_Technical_Papers_2018_Inf_Doc_6_20525_EN.pdf, accessed 6 September 2019).

13. WHO Framework Convention on Tobacco Control. Guidelines for implementation of Article 5.3. 2008 (https://www.who.int/fctc/ guidelines/adopted/article_5_3/en/, accessed 10 September 2019). 